\title{
Study of Shale Gas Debris’ Fractal Theory and Rock Drillability
}

\author{
Jianbin Wang
}

Petroleum Engineering College, Yangtzue University, Wuhan 430100, China

Yan Zhang

Earth Sciences College, Yangtzue University, Wuhan 430100, China

Hongfeng Zhou \& Hui Guo

The Erlian Filiale of HuaBei Oilfield Company, Rengqiu 062550, China

Hongqing Lu

Guangxi beibu gulf airlines co., LTD, Nanning 530000, China

\section{Qicheng Zhou}

Zhongyuan petroleum engineering company, Puyang 457100, China

ABSTRACT: With the developing of shale gas industry, in order to predict rock drillability in drilling time, we should set up the rock drillability profile, which has significant meaning. The article introduces the fractal theory briefly and gives detailed theoretical derivation on fractal dimension D. It has many disadvantages in actual production like short of core and high-cost. In this article, it uses upward shale gas debris to study rock drillability. In view of the FuLing-shale-gas-blocks, this article establishes a relationship between fractal dimension and drillability of extremum, the model has high fitting degree, which has considerable meaning for the actual production.

KEYWORD: Fu-Ling area; Debris; Fractal; Drillability; Fractal dimension

\section{THEORETICAL DERIVATION OF FRACTAL DIMENSION}

In nature, many irregular things can't be described by Euclidean geometry, while this problem can be solved by Fractal theory (Botsis J et al, 1987). For example the Menger Sponge, the appearance of a cube is three-dimensional, but actually sponge's structure is based on many chaotic micropore. When under a certain pressure, the sponge will become a flat surface, and then it became two-dimensional. This says that the appearance of a cube is actually part of 3-D structure, the real dimension is greater than 2 but less than 3 . So we can give a logical conclusion, Euclidean geometry just only reflects the apparent phenomenon of object, however fractal dimension describes the internal characteristics of the object and reveals the inherent law.

According to the fractal theory, a relatively independent part of object is the image of the whole and microcosm in a way. Bit breaks rock constantly in drilling time, debris morphology show irregular shape, and the last it becomes smaller and smaller. Different sizes of debris has self-similarity in the overall form and partial form, so we can use fractal theory to study upward debris and establish the relationship with rock dillability (Li Shibin et al, 2007).

Theoretical model of fragments fractal distribution:

$$
N=C r^{-D}
$$

In the formula, $\mathrm{r}$ represents the debris' diameter, $\mathrm{N}$ represents the number of debris corresponding to $\mathrm{r}$, $\mathrm{C}$ is a constant, $\mathrm{D}$ represents fractal dimension.

Assumptions that a cube of side length is a, and broken base is B (B is greater than or equal to 2), so the cube of side length is $\mathrm{a} / \mathrm{B}$ when broken in first time, and so on, the cube of side length is $\mathrm{a} / \mathrm{B}^{\mathrm{m}}$ when broken $\mathrm{m}$ time (Ma Hai et al, 2008) (Mandelbrot B $B$, 1982). According to theoretical fractal distribution model, we give following formula.

$N_{m}=C r_{m}^{-D}=C a^{-D} B^{m D}$

In the formula, $\mathrm{N}_{\mathrm{m}}$ represents the number of debris corresponding to $\mathrm{rm}_{\mathrm{m}}$. $\mathrm{N}_{\mathrm{rm}}$ represents the adding up debris corresponding from $\mathrm{r}_{1}$ to $\mathrm{r}_{\mathrm{m}}$.

$$
\begin{aligned}
N_{r m} & =N_{1}+N_{2}+N_{3}+\ldots \ldots+N_{m} \\
& =C a^{-D}\left(B^{D}+B^{2 D}+B^{3 D}+\ldots \ldots+B^{m D}\right) \\
& =C a^{-D} \frac{B^{D}\left(B^{m D}-1\right)}{B^{D}-1}
\end{aligned}
$$

Combined with fractal dimension, $\mathrm{D}$ is greater than or equal to 1.73 given in the document $(\mathrm{Li}$ Shibin et al, 2007), when $\mathrm{m}$ is greater than or equal to 4 , then $\mathrm{B}^{\mathrm{mD}}$ is greater than or equal to 1 . So (3) can be changed to the following formula.

$N_{r m}=\frac{C B^{D}}{B^{D}-1} a^{-D} B^{m D}=\frac{C B^{D}}{B^{D}-1} r_{m}^{-D}=C_{1} r_{m}^{-D}$

In the formula, $\mathrm{C}_{1}$ is a constant. Due to a large quantity of debris, it's inconvenient in statistics. The article turn to research relationship between part of debris' quality and debris' diameter. We can get de- 
bris' quality from electronic scales and scales from sieve mesh.

$$
N_{x}=C_{1} r_{\min }^{-D}-C_{1} x^{-D}
$$

In the formula, $\mathrm{N}_{\mathrm{x}}$ represents the number of debris corresponding to less than diameter $\mathrm{x}$, $\mathrm{r}_{\mathrm{min}}$ represents debris' minimun diameter.

$$
\begin{aligned}
M_{r} & =\sum_{x=0}^{r} \frac{4}{3} \pi x^{3} \rho \Delta N_{x} \\
& =\sum_{x=0}^{r} \frac{4}{3} \pi \rho(-C)(-D) x^{2-D} \Delta x
\end{aligned}
$$

In the formula, $\mathrm{M}_{\mathrm{r}}$ represents the quality of debris corresponding to less than sieve mesh diameter $\mathrm{r}, \mathrm{x}$ represents any debris' diameter from 0 to $r, \rho$ represents density. We can change (6) to (7) through differential and integral fundamental theorem.

$$
M_{r}=\frac{4}{3} \pi \rho C D \int_{0}^{r} x^{2-D} d x=\frac{4}{3} \pi \rho C D \frac{r^{3-D}}{3-D}
$$

then (8) can be obtained

$$
\frac{M_{r}}{M_{0}}=\frac{\frac{1}{3-D} \cdot r^{3-D}}{\frac{1}{3-D} \cdot r_{\max }^{3-D}}=\left(\frac{r}{r_{\max }}\right)^{3-D}
$$

In the formula, $\mathrm{M}_{\mathrm{r}} / \mathrm{M}_{0}$ represents the quality percentage of debris corresponding to less than sieve mesh diameter $r, M_{0}$ represents the total debris' quality, rmax represents the debris' maximum diameter.

Based on theoretical model of fragments fractal distribution, the article gives actual fractal distribution regularity about fragments. If condition is satisfied, the expression of both expression forms are consistent. The article gives detailed theoretical derivation on fractal dimension $\mathrm{D}$, at the same time, we establishes monadic linear regression relationship between $\ln \left(\mathrm{M}_{\mathrm{r}} / \mathrm{M}_{0}\right)$ and $\ln \left(\mathrm{r} / \mathrm{r}_{\max }\right)$. The slope of regression straight line is 3 minus $\mathrm{D}$ in rectangular coordinate and thus we can get fractal dimension $\mathrm{D}$.

\section{DETERMINE THE DEBRIS' DIMENSION D}

This paper selects the stratigraphic position including Longtan, Maokou, Qixia, HanJiadian, Xiaoheba and Longmaxi. The lithology mainly contains mud and shale. During the experiment, the quality of debris is controlled at $100 \mathrm{~g}$. We should dry off debris, so as to enhance the accuracy of experimental date.

In this experiment, the sieve mesh diameter are $4.75 \mathrm{~mm}, 2.00 \mathrm{~mm}, 1.00 \mathrm{~mm}, 0.5 \mathrm{~mm}, 0.35 \mathrm{~mm}$, respectively. The vibration time of the separator is set to 5 minutes. Debris is weighted (shown in table one) and recorded for analysis (shown in figure one) on each level.

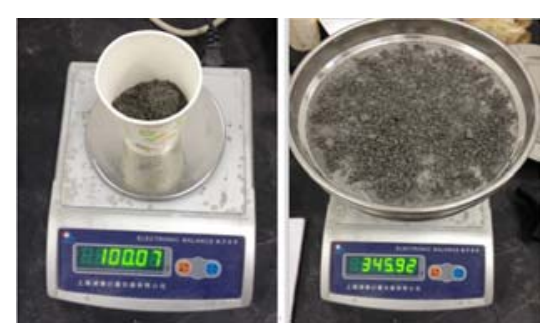

Fig1 debris weighing

Tab.1 Upward debris quality percentage

\begin{tabular}{|c|c|c|c|c|c|c|}
\hline \multirow{2}{*}{$\begin{array}{c}\text { stratigraphic } \\
\text { position }\end{array}$} & \multirow{2}{*}{ Depth(m) } & \multicolumn{5}{|c|}{ sieve mesh diameter(mm) } \\
\cline { 3 - 6 } & & 0.35 & 0.5 & 1 & 2 & 4.75 \\
\cline { 3 - 6 } & $1061-1062$ & 6.12 & 11.19 & 38.27 & 78.56 & 91.21 \\
\hline Longtan & $1245-1248$ & 5.05 & 13.12 & 39.11 & 71.07 & 86.25 \\
\hline Maokou & $1290-1294$ & 6.81 & 15.12 & 32.15 & 76.62 & 91.13 \\
\hline Qixia & $1630-1631$ & 6.11 & 17.23 & 36.47 & 47.25 & 77.68 \\
\hline Hanjiadian & $2082-2086$ & 7.83 & 21.21 & 33.25 & 43.54 & 76.17 \\
\hline Xiaoheba & $2210-2212$ & 8.15 & 23.57 & 31.25 & 55.15 & 72.17 \\
\hline Longmaxi & 225 &
\end{tabular}




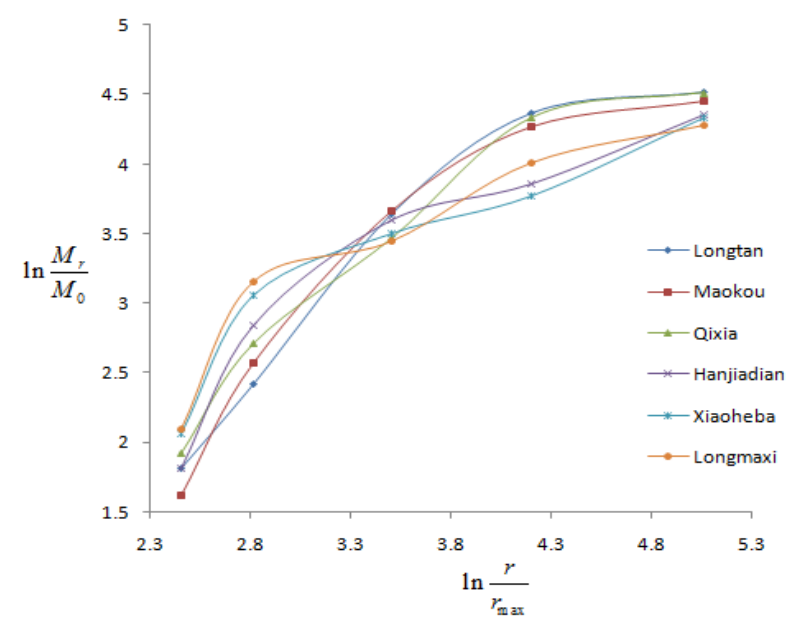

Fig2 Fractal debris of different layer

We have analyzed the six layers and drawn a diagram of the relationship between $\ln \left(\mathrm{M}_{\mathrm{r}} / \mathrm{M}_{0}\right)$ and $\ln (\mathrm{r} / \mathrm{rmax})$.

The statistics and analysis for the results of each sample debris screening have been carried out. From the result, we calculate the fractal dimension $\mathrm{D}$ and relative coefficient.

Tab2 Fractal dimension of different layers

\begin{tabular}{|l|l|l|}
\hline $\begin{array}{l}\text { Stratigraphic posi- } \\
\text { tion }\end{array}$ & $\begin{array}{l}\text { Fractal dimension } \\
\text { D }\end{array}$ & $\begin{array}{l}\text { Relative coeffi- } \\
\text { cient }\end{array}$ \\
\hline Longtan & 1.924 & 0.901 \\
\hline Maokou & 1.935 & 0.876 \\
\hline Qixia & 2.005 & 0.918 \\
\hline Hanjiadian & 2.120 & 0.875 \\
\hline Xiaoheba & 2.237 & 0.884 \\
\hline Longmaxi & 2.251 & 0.860 \\
\hline
\end{tabular}

The relative coefficients are all above 0.86 , so we can see that fractal dimension D and relative coefficient have good correlation. This conforms to the fractal theory. Fractal dimension increases with depth, which also conforms to the compaction law.

\section{THE RELATIONSHIP BETWEEN FRACTAL DIMENSION AND ROCK DRILLABILITY}

The research of rock drillability is based on laboratory experimental data. Automatic tester is used to get the drillability extreme value (Wang Qianyuan et al, 1994) (Xie Heping, 1997) (Yang Minghe et al, 2008) (Yan Tie et al, 2007), so as to establish the relationship between rock dillability and fractal dimension in Fu-Ling area. Curve of least square method has been used to enhance fitting accuracy. Setting a function $S(x)$, so the value in the node is $\mathrm{S}\left(\mathrm{x}_{\mathrm{i}}\right)(\mathrm{i}=1,2 \ldots \ldots \mathrm{n})$. And then we can get an approximate one $S(x)=\sum_{i=0}^{n} a_{j} \varphi_{j}(x)$. The power function $\mathrm{w}(\mathrm{x})$ is not used here because of the consistency of the data of different points (Yan Tie et al, 2014) (Zhang Hui et al, 2006).

$$
P=\sum_{i=0}^{m}\left[S\left(x_{i}\right)-y_{i}\right]^{2}=\sum_{i=0}^{m}\left[\sum_{i=0}^{n} a_{j} \varphi_{j}\left(x_{i}\right)-y_{i}\right]^{2}
$$

(9)formula is intended to find the minimun of P. According to the essential conditions of function extreme value, we can get (10)formula.

$\frac{\partial P}{\partial a_{k}}=2 \sum_{i=0}^{m}\left[S\left(x_{i}\right)-y_{i}\right] \varphi_{k}\left(x_{i}\right)=0$

(10) simplifies (11)

$\sum_{j=0}^{n}\left[\sum_{i=0}^{m} \varphi_{k}\left(x_{i}\right) \varphi_{j}\left(x_{i}\right)\right] a_{j}=\sum_{i=0}^{m} \varphi_{k}\left(x_{i}\right) y_{i}$

The mathematical solution of (11) is established and the matrix equation is established. (if we choose linear equation then $\varphi_{2}(x)=0, a_{2}=0$ )

$$
\left(\begin{array}{lll}
\sum_{i=0}^{m} \varphi_{0}\left(x_{i}\right) \varphi_{0}\left(x_{i}\right) & \sum_{i=0}^{m} \varphi_{0}\left(x_{i}\right) \varphi_{1}\left(x_{i}\right) & \sum_{i=0}^{m} \varphi_{0}\left(x_{i}\right) \varphi_{2}\left(x_{i}\right) \\
\sum_{i=0}^{m} \varphi_{1}\left(x_{i}\right) \varphi_{0}\left(x_{i}\right) & \sum_{i=0}^{m} \varphi_{1}\left(x_{i}\right) \varphi_{1}\left(x_{i}\right) & \sum_{i=0}^{m} \varphi_{1}\left(x_{i}\right) \varphi_{2}\left(x_{i}\right) \\
\sum_{i=0}^{m} \varphi_{2}\left(x_{i}\right) \varphi_{0}\left(x_{i}\right) & \sum_{i=0}^{m} \varphi_{2}\left(x_{i}\right) \varphi_{1}\left(x_{i}\right) & \sum_{i=0}^{m} \varphi_{2}\left(x_{i}\right) \varphi_{2}\left(x_{i}\right)
\end{array}\right)\left(\begin{array}{l}
a_{0} \\
a_{1} \\
a_{2}
\end{array}\right)=\left(\begin{array}{l}
\sum_{i=0}^{m} \varphi_{0}\left(x_{i}\right) y_{i} \\
\sum_{i=0}^{m} \varphi_{1}\left(x_{i}\right) y_{i} \\
\sum_{i=0}^{m} \varphi_{2}\left(x_{i}\right) y_{i}
\end{array}\right)
$$

The fractal dimension is independent variable and the drillability extreme value is the function of the variable. Though the data in table 3 , we find that scatter points conform to linear or quadric curve. So we assume linear equation is $\mathrm{y}=\mathrm{a}_{0}+\mathrm{a}_{1} \mathrm{x}$ and quadric curve equation is $\mathrm{y}=\mathrm{a}_{0}+\mathrm{a}_{1} \mathrm{x}+\mathrm{a}_{2} \mathrm{x}^{2}$.

Tab3 Fractal dimension of different layers and drillabili

\begin{tabular}{|l|l|l|}
\hline $\begin{array}{l}\text { Stratigraphic po- } \\
\text { sition }\end{array}$ & $\begin{array}{l}\text { Fractal dimen- } \\
\text { sion D }\end{array}$ & Rock drillability Kd \\
\hline Longtan & 1.924 & 4.89 \\
\hline Maokou & 1.935 & 5.38 \\
\hline Qixia & 2.005 & 5.84 \\
\hline Hanjiadian & 2.120 & 6.18 \\
\hline Xiaoheba & 2.237 & 6.45 \\
\hline Longmaxi & 2.251 & 6.61 \\
\hline
\end{tabular}




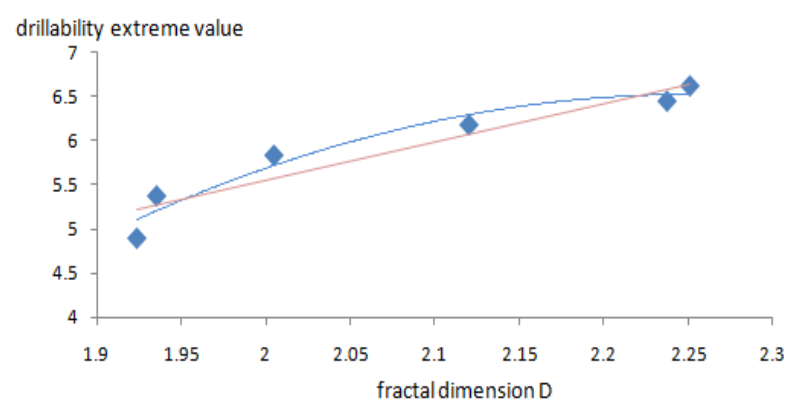

Fig3 Fractal dimension and drillability scatter plot

According to the assumptive linear equation, the matrix equation is established.

$\left(\begin{array}{cc}6 & 12.472 \\ 12.472 & 26.0316\end{array}\right)\left(\begin{array}{l}a_{0} \\ a_{1}\end{array}\right)=\left(\begin{array}{l}35.35 \\ 73.9372\end{array}\right)$

We calculate the equation $\mathrm{y}=4.286 \mathrm{x}-3.018$ and relative coefficient $\mathrm{R}^{2}=0.8978$.

According to the assumptive quadric curve equation, the matrix equation is established.

$\left(\begin{array}{ccc}6 & 12.472 & 26.0316 \\ 12.472 & 26.0316 & 54.5557 \\ 26.0316 & 54.5557 & 114.7988\end{array}\right)\left(\begin{array}{l}a_{0} \\ a_{1} \\ a_{2}\end{array}\right)=\left(\begin{array}{l}35.35 \\ 73.9372 \\ 155.2677\end{array}\right)$

We calculate the equation $y=-9.184 x^{2}+42.645 x-$ 42.907 and relative coefficient $\mathrm{R}^{2}=0.9412$. Compared the relative coefficient of two cases, we decide to use quadric curve equation to establish the relationship between fractal dimension and rock dillability.

\section{CONCLUSION}

(1) After the study of upward debris on the distribution, it indicates that the rock fragment distribution has good fractal characteristics and the relative coefficient is all above 0.86 . So we can use the fractal dimension to analysis the rock distribution.

(2) In the experiment, a part of debris will be remained on the sieve and it will affect the accuracy of experimental data due to its difficulty to be removed.

(3) We have established the relationship between the fractal dimension and rock drillability. Curve of least square method has been used to reduce the error between the actual and the theoretical data. We have chosen the method of quadratic curves which has highly fitting degrees.

(4) This method of using upward debris is more simple and cheaper. It could take sample of debris constantly in drilling time. This article has certain theoretical and application value.

\section{REFERENCES}

Botsis J, Kunin B.On self-similarity of crack layer[J].Int. J Fracturing, 1987, 35: 51-56.
Li Shibin, Li Wei, You Hongli. Classification Methods of Rock Drillability Based On The Fractal Theory[J]. Natural Gas Industry, 2007, 27(10): 63-66.

Ma Hai, Wang Yanjiang, Wei Maoan,et al. A novel method for predicting formation drillability[J].Actal Petrolei Sinica, 2008, 29 (5): 761-765.

Mandelbrot B B. The fractal geometry of nature[M].New York;Macmillanm, 1982: 37-60

Wang Qianyuan, Zhang Qing. Fractal Fragmentation with unequal probability and the fractal of fragments in a Limited scale[J],Rock Mechanics and Engineering, 1994, 13(2): 109117.

Xie Heping. Introduction to fractal-rock mechanics[M]. Beijing;Science Press, 1997: 240-246.

Yang Minghe, Zhai Yinghu, Xia Hongnan. Study on calculation method for numerical simulation of drillable field in regional formation[J],petroleum geology and engineering, 2008, 22(3):82-84.

Yan Tie, Li Wei, Li Shibin, Breaking cuttings mechanism of cone bits and fractalm ethod for rock drillability[J]. 2007, 29(2). 27-30.

Yan Tie, Zhang Yang, Du Shuming. Energy Efficiency Evaluation Model In Drilling Based On Fractal Fragmentation Characteristic of Rock Cuttings[J], Rock Mechanics and Engineering, 2014, 33(1): 3158-3163.

Zhang Hui, Gao Deli. A New method for predicting drillability of undrilled formation[J]. Actal Petrolei Sinica, 2006, 27(1):97-100. 